\title{
Fluxes and gas transfer rates of the biogenic trace gas DMS derived from atmospheric gradients
}

\author{
Hendrik J. Zemmelink, John W. H. Dacey, Eric J. Hintsa, and Wade R. McGillis \\ Woods Hole Oceanographic Institution, Woods Hole, Massachusetts, USA
}

Winfried W. C. Gieskes, Wim Klaassen, Henk W. de Groot, and Hein J. W. de Baar Marine Biology, University of Groningen, Haren, Netherlands

Received 24 January 2003; revised 20 August 2003; accepted 21 October 2003; published 30 June 2004.

[1] Gas transfer rates were determined from vertical profile measurements of atmospheric dimethylsulfide (DMS) gradients over the equatorial Pacific Ocean obtained during the GasEx-2001 cruise. A quadratic relationship between gas transfer velocity and wind speed was derived from the DMS flux measurements; this relationship was in close agreement with a parameterization derived from relaxed eddy accumulation measurements of DMS over the northeastern Pacific Ocean. However, the GasEx-2001 relationship results in gas transfer rates that are a factor 2 higher than gas transfer rates calculated from a parameterization that is based on coincident eddy correlation measurements of $\mathrm{CO}_{2}$ flux. The measurement precision of both the profiling and eddy correlation techniques applied during GasEx-2001 is comparable; the two gas transfer data sets are in agreement within their uncertainty. Differences in the number of samples and the wind speed range over which $\mathrm{CO}_{2}$ and DMS fluxes were measured are likely causes for the observed discrepancy. INDEX TERMS: 4504 Oceanography: Physical: Air/sea interactions (0312); 4820 Oceanography: Biological and Chemical: Gases; 1615 Global Change: Biogeochemical processes (4805); 0330 Atmospheric Composition and Structure: Geochemical cycles; KEYWORDS: dimethylsulfide (DMS), atmospheric gradients, micrometeorology, GasEx-2001

Citation: Zemmelink, H. J., J. W. H. Dacey, E. J. Hintsa, W. R. McGillis, W. W. C. Gieskes, W. Klaassen, H. W. de Groot, and H. J. W. de Baar (2004), Fluxes and gas transfer rates of the biogenic trace gas DMS derived from atmospheric gradients, J. Geophys. Res., 109, C08S10, doi:10.1029/2003JC001795.

\section{Introduction}

[2] Dimethylsulfide (DMS), a biogenic gas that originates from the oceans, plays an important role in atmospheric chemistry [Andreae and Crutzen, 1997]. Observations in the marine boundary layer of the Southern Hemisphere strongly suggest that DMS and its atmospheric oxidation products participate in processes of climate regulation and the reactivity of the atmosphere [Ayers and Gillett, 2000]. Quantification of the sea-to-air flux remains a prerequisite for assessing the environmental impact of DMS. The exchange of DMS $\left(\mathrm{F}, \mathrm{mol} \mathrm{m} \mathrm{m}^{-2} \mathrm{~d}^{-1}\right)$ between the ocean and the atmosphere is commonly estimated from the air-sea concentration gradient $(\Delta \mathrm{C})$ and an empirically determined gas transfer rate $\left(\mathrm{k}_{\mathrm{gas}}\right)$,

$$
\mathrm{F}=\mathrm{k}_{\mathrm{gas}} \Delta \mathrm{C} \text {. }
$$

Most parameterizations of transfer rates are based on wind tunnel, radiocarbon, or tracer measurements, and relate $\mathrm{k}_{\mathrm{gas}}$ to sea surface temperature and wind speed. Unfortunately, the most commonly applied parameterizations, of Liss and

Copyright 2004 by the American Geophysical Union. 0148-0227/04/2003JC001795\$09.00
Merlivat [1986] and of Wanninkhof [1992], differ by more than a factor of 2 in their prediction of exchange rates and therefore the flux [Kettle and Andreae, 2000]. Studies of DMS and sulfur cycling over the oceans [Putaud and Nguyen, 1996; Yvon et al., 1996] support the higher estimates of gas transfer rates. On the other hand, studies based on the use of dissolved tracer gases support lower estimates [Liss et al., 1993; Nightingale et al., 2000]. There is currently no well-constrained relationship between gas transfer rates and wind speed that can be used for the reliable prediction of in situ DMS fluxes. Liss [1999] has stated that progress is most likely to come once a micrometeorological technique is developed that can measure DMS fluxes across the sea surface.

[3] In recent years, micrometeorological techniques, such as the gradient flux (GF) and relaxed eddy accumulation (REA) techniques, have been applied for the measurement of DMS fluxes, and the subsequent derivation of the gas transfer rate [McGillis et al., 2001; Zemmelink et al., 2002; Hintsa et al., 2004; Zemmelink et al., 2004]. Most of these studies suggest high DMS transfer rates. However, GF and REA techniques do not allow the measurement of the absolute flux and rely on models that incorporate wind and atmospheric stability measurements. These models have been extensively tested over terrestrial systems, but their 
application in the marine environment is still relatively new. Although Edson and Fairall [1998] concluded that MoninObukhov similarity theory (the basis of the GF technique) is valid over the sea, as long as it is applied above the wave boundary layer, further tests are necessary before both REA and GF can be applied with confidence at sea. The first studies that aimed at the intercalibration of REA and GF techniques, used in tandem for the measurement of DMS fluxes, resulted in different gas transfer rates between the two methods [Hintsa et al., 2004; Zemmelink et al., 2004]. The difference could not be attributed to experimental error. One environmental forcing factor, i.e., atmospheric stability, was also ruled out as an explanation of the discrepancy. Both sets of results were reasonable, however: REA measurements were in agreement with gas transfer velocities obtained from eddy correlation measurements of $\mathrm{CO}_{2}$ fluxes in a shelf sea [Jacobs et al., 1999] and GF measurements were in agreement with estimates based on the parameterization of Liss and Merlivat [1986]. It was concluded that there is at present no reason to prefer the use of one technique over the other in the marine environment.

[4] Better insight into the applicability of micrometeorological systems in the marine environment and processes that influence gas exchange will come from experiments that aim at the intercalibration of techniques and/or at the measurement of fluxes of different gases. The transfer rates of different gases (or gases at different temperatures) can then be related through the Schmidt number (Sc) using $\mathrm{k}_{\mathrm{a}}=\mathrm{k}_{\mathrm{b}}\left(\mathrm{Sc}_{\mathrm{a}} / \mathrm{Sc}_{\mathrm{b}}\right)^{\mathrm{n}}$ where $\mathrm{n}$ is the Schmidt number dependence $(-2 / 3$ for smooth water surfaces, wind speed $\leq 3.6 \mathrm{~m} \mathrm{~s}^{-1}$, and $-1 / 2$ for rough surfaces, wind speed $>$ $3.6 \mathrm{~m} \mathrm{~s}^{-1}$ ). In this study we present results derived from GF measurements of DMS fluxes over the equatorial Pacific Ocean performed during the GasEx-2001 experiment. In addition, these GF results from GasEx-2001 are compared with eddy correlation measurements of the $\mathrm{CO}_{2}$ flux conducted during the same cruise and with results from previous measurements over the northeastern Pacific Ocean. Finally, possible reasons for the discrepancy between the results of the different measurements are discussed.

\section{Materials and Methods}

[5] The GasEx-2001 cruise was an interdisciplinary airsea gas exchange experiment conducted aboard the NOAA ship Ronald H. Brown during February 2001. The study site was in the eastern equatorial Pacific along $3^{\circ} \mathrm{S}$ between $125^{\circ} \mathrm{W}$ and $130^{\circ} \mathrm{W}$.

[6] With the GF technique [Businger et al., 1971], the flux is derived from the difference in concentration $\left(\mathrm{C}\right.$, mol m $\mathrm{m}^{-3}$ ) between two or more elevations using Monin-Obukhov similarity theory [Monin and Obukhov, 1954],

$$
\mathrm{C}(\mathrm{z})=\frac{\mathrm{C} *}{\mathrm{k}}\left(\ln (\mathrm{z})-\Psi\left(\frac{\mathrm{z}}{\mathrm{L}}\right)\right)
$$

where $\mathrm{C}(\mathrm{z})$ is the DMS concentration at height $z(\mathrm{~m}), \Psi$ is the integrated flux profile function that corrects for atmospheric stability [Paulson, 1970], L is the Obukhov length, and $\mathrm{k}$ is the von Karman constant (0.4). The value of $\mathrm{C}_{*}$ is determined from the least squares fitted slope of $\mathrm{C}(\mathrm{z})$ as a function of $\ln (\mathrm{z})-\Psi(\mathrm{z} / \mathrm{L})$, the stability-corrected height. Next the DMS flux is calculated using

$$
\mathrm{F}_{\mathrm{DMS}}=-\mathrm{C}_{*} \mathrm{u} *
$$

where $\mathrm{u}_{*}\left(\mathrm{~m} \mathrm{~s}^{-1}\right)$ is the friction velocity, derived from eddy correlation wind measurements. The uncertainty of the estimated flux is expressed in this study as the $95 \%$ confidence interval of $C_{*}$, based on the fit of $C$ to $\ln (\mathrm{z})-\Psi(\mathrm{z} / \mathrm{L})$. The uncertainty in $\mathrm{u}_{*}$ has not been calculated in this study but is of the same order as the uncertainty in $\mathrm{C}_{*}$.

[7] Air was sampled at 40-min intervals using inlets at $2.5,4,6$, and $8 \mathrm{~m}$ above the sea surface from a boom that extended $10 \mathrm{~m}$ off the bow. The elevation of the inlet at $8 \mathrm{~m}$ was adjustable and sometimes used to take duplicate samples at the other elevations. Sampled air was drawn at

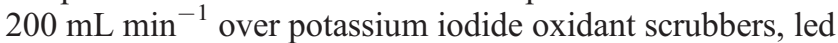
through $30 \mathrm{~m}$ of Teflon tubing and collected in Tedlar bags following the procedure described by Zemmelink et al. [2002]. The collected air was brought to the same temperature and the effect of density fluctuations on the DMS flux measurements was further avoided by drying the air over a cold finger prior to concentration of DMS on a Tenax trap, at a flow rate of $300 \mathrm{~mL} \mathrm{~min}^{-1}$. Both the cold finger and the Tenax trap were cooled to $-15^{\circ} \mathrm{C}$. This is necessary for the GC analysis, and also removes the need for the Webb correction. Subsequently, the DMS concentration was determined by desorption of the DMS into a Sievers 350B gas chromatograph. Sulfur compounds were separated on a Chromosil-330 column and analyzed with a sulfur chemiluminescence detector. A triplicate analysis was conducted from each sampling bag. The concentration of DMS in the surface water was determined from water samples taken during each flux measurement. Aqueous DMS was analyzed following the procedure described by Dacey et al. [1998].

[8] Transfer velocities were calculated using $\mathrm{k}_{\text {gas }}=\mathrm{F} /$ $\left(\mathrm{C}_{\mathrm{w}}-\mathrm{C}_{\mathrm{a}} / K_{\mathrm{H}}\right)$ where $\mathrm{k}_{\text {gas }}$ is the total gas transfer velocity, which results from a waterside transfer velocity $\left(\mathrm{k}_{\mathrm{w}}\right)$ and an airside transfer velocity $\left(\mathrm{k}_{\mathrm{a}}\right), \mathrm{C}_{\mathrm{w}}$ is the waterside DMS concentration, $\mathrm{C}_{\mathrm{a}}$ is the atmospheric DMS concentration, determined from the measurements at $2.5 \mathrm{~m}$ elevation, and $K_{\mathrm{H}}$ is the dimensionless Henry coefficient $\left(K_{\mathrm{H}}=\mathrm{H} / \mathrm{RT}\right.$ where $\mathrm{H}$ is the Henry constant of DMS calculated following Dacey et al. [1984], $\mathrm{R}$ is the universal gas constant, and $\mathrm{T}$ is the absolute temperature).

[9] In order to express the transfer velocity in term of $\mathrm{k}_{\mathrm{w}}$, the effect of the airside transfer velocity has to be removed as suggested by McGillis et al. [2000]: $\mathrm{k}_{\mathrm{w}}=\mathrm{k}_{\mathrm{gas}} /(1-\gamma)$, where $\gamma$ is the airside gradient factor affecting the flux. The value of $\gamma$ is calculated from the ratio of the water and airside transfer velocities: $\gamma=1 /\left(1+\mathrm{k}_{\mathrm{a}} / \omega \mathrm{k}_{\mathrm{w}}\right)$, with $\omega$ the Ostwald solubility coefficient for DMS from Dacey et al. [1984]. The airside transfer velocity $\left(\mathrm{k}_{\mathrm{a}}\right)$ is calculated from models of water vapor transfer velocities as suggested by Kondo [1975] and Liu et al. [1979]. Waterside transfer velocities $\left(\mathrm{k}_{\mathrm{w}}\right)$ for the $\gamma$ correction are given by the model of Wanninkhof [1992]. The correction is on the order of $5 \%$ at wind speeds up to 

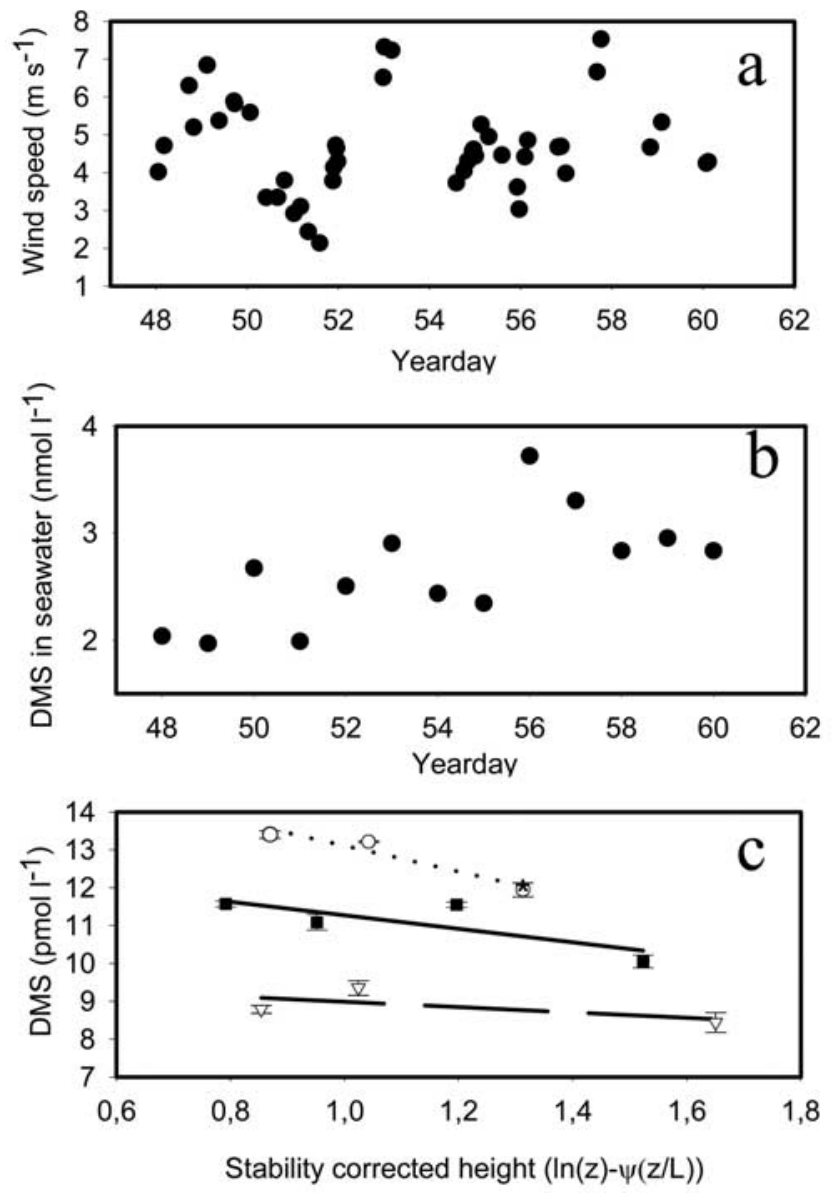

Figure 1. (a) Wind speed $\left(\mathrm{m} \mathrm{s}^{-1}\right)$ at $10 \mathrm{~m}$. (b) Surface water DMS concentration ( $\mathrm{nmol} \mathrm{L} \mathrm{L}^{-1}$ ) averaged over each day. (c) Atmospheric DMS (pmol L${ }^{-1}$ ) as a function of the stability-corrected elevation. The dotted line is the best fit through an early morning profile (open circles), $\mathrm{U}=$ $6.8 \mathrm{~m} \mathrm{~s}^{-1}$, slope $=-3.2, \mathrm{R}^{2}=0.92$; the solid line is the best fit through a mid afternoon profile (solid squares), $\mathrm{U}=$ $5.4 \mathrm{~m} \mathrm{~s}^{-1}$, slope $=-1.8, \mathrm{R}^{2}=0.64$; the dashed line is the best fit through a mid morning profile (open triangles), $\mathrm{U}=$ $5.8 \mathrm{~m} \mathrm{~s}^{-1}$, slope $=-0.1, \mathrm{R}^{2}=0.43$. Error bars are 1 standard deviation from the mean. The asterisk indicates a duplicate sample taken along with the open circles.

$5 \mathrm{~m} \mathrm{~s}^{-1}, 10 \%$ at $7-10 \mathrm{~m} \mathrm{~s}^{-1}$ and $16 \%$ or more at higher wind speeds [Zemmelink et al., 2004].

\section{Results and Discussion}

[10] The atmosphere was slightly unstable during the experiment with the water temperature higher than the air temperature: $26.9^{\circ}$ and $26.3^{\circ} \mathrm{C}$, respectively. Wind speed ranged from 2 to $7.5 \mathrm{~m} \mathrm{~s}^{-1}$, averaging $5 \mathrm{~m} \mathrm{~s}^{-1}$ (Figure 1a). The seawater DMS concentration ranged from 2 to $3.7 \mathrm{nM}$, with an average of $2.7 \mathrm{nM}$ (Figure 1b), consistent with values for this area listed in the database of Kettle et al. [1999] and values of approximately $2.0( \pm 0.7) \mathrm{nM}$ found by Bates et al. [1993] in the central equatorial Pacific Ocean, while Yvon et al. [1996] found an average seawater DMS concentration of $4.1 \mathrm{nM}$ south-west of the GasEx-2001 cruise.
[11] The average DMS concentration in 48 series of three profiles collected at 2.5, 4, and $6 \mathrm{~m}$ were 10.1, 9.2 and $8.7 \mathrm{pmol} \mathrm{L}^{-1}$, respectively. These atmospheric concentrations are lower than those found by Yvon et al. [1996] but consistent with atmospheric DMS found in the marine boundary layer remote from the continents [Andreae, 1990; Quinn et al., 1993]. The decreasing DMS concentration with height (Figure 1c), confirms an efflux. However, the uncertainty at the $95 \%$ confidence interval for $\mathrm{C}_{*}$ (and therefore of the estimated flux and transfer velocities) was large, which for some measurements does not exclude the possibility of a flux of DMS into the water (Figure 2). A problem involved in the application of the gradient method is its sensitivity to flow distortion and platform motion; both become more pronounced with increasing wind speeds. The relative uncertainty of our measurements (expressed as the percentages of the flux) did not show a dependence on wind speed so we could not straightforwardly attribute the error in our flux measurements to flow distortion around the ship's hull. However, the uncertainty is not caused by the analytical procedure that was used to determine the DMS concentration in the sampled air: The reproducibility of a triplicate analysis was good, usually within $10 \%$. In addition, DMS values deviating from a log linear slope in any one profile could not be attributed to fouling of the sample system; duplicate air samples taken from the same elevation did not show a significant difference (and the different inlets showed no signs of any systematic bias).

[12] Stochastic measurement errors may still have affected the profiles so it was decided to use all 48 measurements for further analysis. Fluxes were positive and increased with increasing wind speeds from $0.2( \pm 4) \mu \mathrm{mol} \mathrm{m}^{-2} \mathrm{~d}^{-1}$ to a maximum of $36( \pm 21) \mu \mathrm{mol} \mathrm{m}{ }^{-2} \mathrm{~d}^{-1}$, with an average of $9.0 \mu \mathrm{mol} \mathrm{m}{ }^{-2} \mathrm{~d}^{-1}$ (Figure 2).

[13] Transfer velocities calculated from the sea surface DMS concentrations and the measured flux varied between 0.5 and $55 \mathrm{~cm} \mathrm{hr}^{-1}$. On average, transfer velocities increased with increasing wind speeds (Figure 3). The transfer velocities were on average higher than those derived from parameterizations between wind speed and

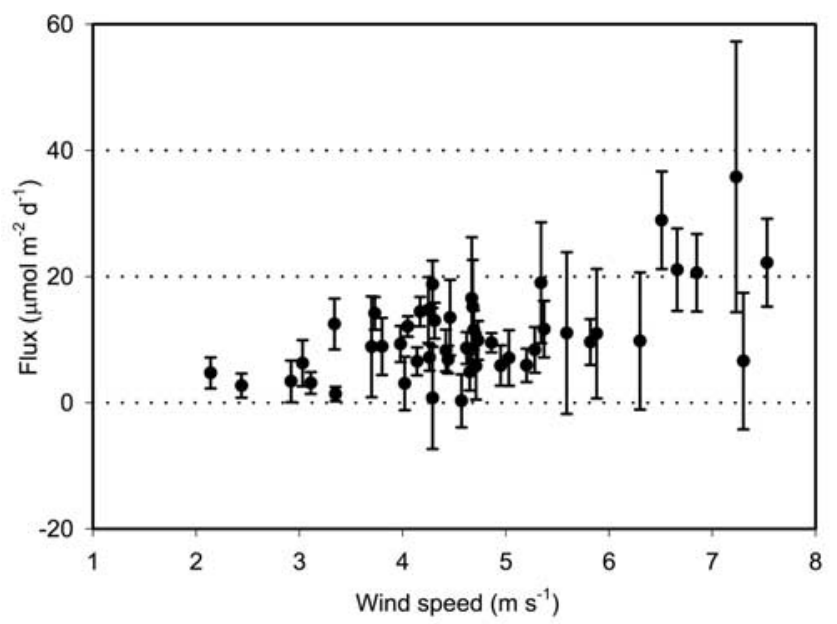

Figure 2. DMS flux $\left(\mu \mathrm{mol} \mathrm{m} \mathrm{m}^{-2} \mathrm{~d}^{-1}\right)$ as a function of wind speed $\left(\mathrm{m} \mathrm{s}^{-1}\right)$. Error bars represent the $95 \%$ confidence interval of the best fit through the profile. 


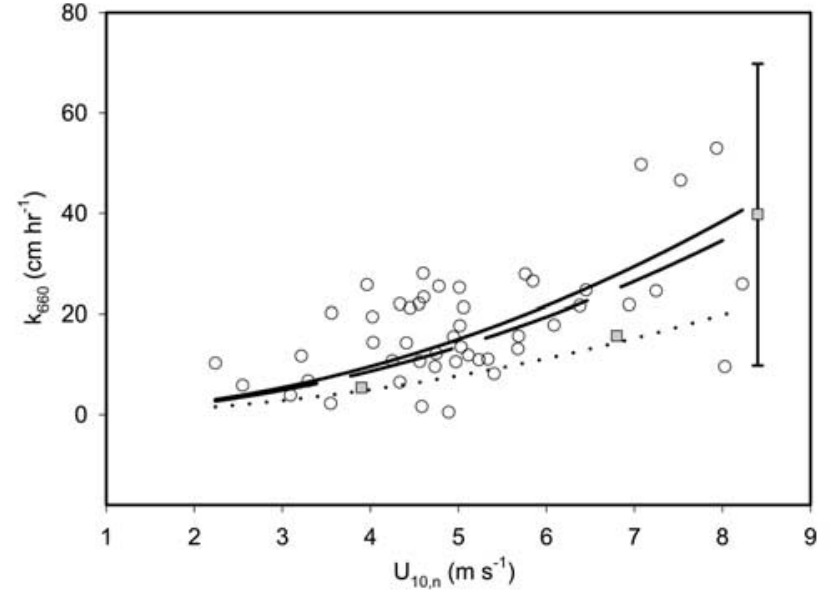

Figure 3. Open circles: gas transfer velocities $\left(\mathrm{cm} \mathrm{hr}^{-1}\right)$, derived from gradient measurements of DMS fluxes during the GasEx-2001 cruise (Figure 2), versus wind speed $\left(\mathrm{m} \mathrm{s}^{-1}\right)$ at $10-\mathrm{m}$ elevation during neutral atmospheric conditions. The shaded squares are the average of gas transfer velocities derived from DMS gradient measurements during the GasEx-1998 cruise $(\mathrm{n}=3)$ conducted in the North Atlantic Ocean. Transfer velocities are normalized to the transfer velocity of $\mathrm{CO}_{2}$ in water at $20^{\circ} \mathrm{C}$ with a salinity of $35 \%$. The solid line is the quadratic fit through the GasEx-2001 results: $\mathrm{k}_{660}=0.60( \pm 0.04) \mathrm{U}_{10}^{2}$. The dashed line is the equation based on eddy correlation measurements of the $\mathrm{CO}_{2}$ flux: $0.54 \mathrm{U}_{10}^{2}$ by Jacobs et al. [1999]. The dotted line is the Wanninkhof [1992] fit: $\mathrm{k}_{660}=$ $0.31 \mathrm{U}_{10}^{2}$.

gas transfer commonly applied for the calculation of fluxes [Liss and Merlivat, 1986; Wanninkhof, 1992]. Nevertheless, the results of GasEx-2001 (hereinafter referred to as GasEx01-GF/DMS) are consistent with the high transfer velocities derived from DMS fluxes found during GasEx1998 conducted in the North Atlantic Ocean (Figure 3, and McGillis et al. [2001]). Moreover, the results from DMS measurements are in agreement with transfer velocities derived from eddy correlation measurements of the carbon dioxide flux (hereinafter referred to as $\mathrm{GasEx} 01-\mathrm{EC} / \mathrm{CO}_{2}$ measurements) conducted by McGillis et al. (Figure 4).

[14] A fit through the GasEx01-GF/DMS data using a quadratic dependence on wind speed resulted in

$$
\mathrm{k}_{660}=0.60( \pm 0.04) \mathrm{U}_{10}^{2} \quad \mathrm{R}^{2}=0.28,
$$

in which $\mathrm{k}_{660}$ is the transfer velocity normalized to the transfer velocity of $\mathrm{CO}_{2}$ in water with a salinity of $35 \%$ at $20^{\circ} \mathrm{C}$ and $\mathrm{U}_{10}\left(\mathrm{~m} \mathrm{~s}^{-1}\right)$ is the wind speed at $10-\mathrm{m}$ elevation under neutral conditions. The exponent in the relationship between $\mathrm{k}_{660}$ and $\mathrm{U}_{10}$ is based on the work of Wanninkhof [1992], who proposed $\mathrm{k}_{660}=0.31 \mathrm{U}_{10}^{2}$ for short-term measurements of wind speed). Equation (4) is nearly equivalent to the relation derived from relaxed eddy accumulation (REA) measurements of DMS flux over the northeastern Pacific during the Fluxes Air-Sea Interaction and Remote Sensing (FAIRS) experiment $\mathrm{k}_{660}=0.61( \pm$ $0.06) \mathrm{U}_{10}^{2}$, but it is different from parameterizations obtained from GF/DMS measurements during the same FAIRS cruise $\mathrm{k}_{660}=0.18( \pm 0.03) \mathrm{U}_{10}^{2}$ [Hintsa et al., 2004; Zemmelink et al., 2004] and different from the relationship derived from the GasEx01-EC/CO $\mathrm{CO}_{2}$ measurements $\mathrm{k}_{660}=0.28( \pm 0.01) \mathrm{U}_{10}^{2}$.

[15] On the basis of the agreement between the constants of the gas transfer relationships derived from GasEx01GF/DMS measurements $(0.60 \pm 0.04)$ and FAIRS-REA/ DMS measurements $(0.61 \pm 0.06)$, we decided to combine both data sets. It is clear that the absolute scatter of $\mathrm{k}_{660}$ in this merged data set increases with increasing wind speed; for a wind speed range of $2 \mathrm{~m} \mathrm{~s}^{-1}<\mathrm{U}<5 \mathrm{~m} \mathrm{~s}^{-1}$ the value of $\mathrm{k}_{660 \mathrm{avg}}=14 \pm 8 \mathrm{~cm} \mathrm{hr}^{-1}$, while for a wind speed range of $6 \mathrm{~m} \mathrm{~s}^{-1}<\mathrm{U}<9 \mathrm{~m} \mathrm{~s}^{-1}$ the value of $\mathrm{k}_{660 \mathrm{avg}}=30 \pm$ $24 \mathrm{~cm} \mathrm{hr}^{-1}$ (where the subscript avg refers to the average). Analysis of $\log$ transformed data, $\ln \left(\mathrm{k}_{660}\right)$ versus $\ln (\mathrm{U})$, showed that the relative scatter remained constant (Figure 5) and that the variance of the two transformed data sets does not significantly differ $(\mathrm{P}>5 \%)$, which implies that pooling the two data sets is legitimate.

[16] The relationship between gas transfer and wind speed derived from the best fit through the log transformed data, with zero intercept, was $\mathrm{k}_{660}=1.28( \pm 0.42)$ $\mathrm{U}^{1.47}( \pm 0.22)\left(\mathrm{R}^{2}=0.35\right)$. Application of a quadratic fit through the $\ln$ transformed data resulted in $\mathrm{k}_{660}=0.48$ $( \pm 0.09) \mathrm{U}_{10}^{2}\left(\mathrm{R}^{2}=0.31\right.$; Figure 6$)$. Both relationships are within the uncertainty of the "global average k" determined from the atom bomb ${ }^{14} \mathrm{C}$ inventory in the ocean $\left(\mathrm{U}_{10}=7.4 \mathrm{~m} \mathrm{~s}^{-1}, \mathrm{k}=22 \mathrm{~cm} \mathrm{hr}^{-1}\right.$ [Broecker et al., 1985]). Values of $\mathrm{k}_{\mathrm{w}}<1$ were excluded from the log transformed data in order to evaluate the effect of low $\mathrm{k}_{\mathrm{w}}$ values on the parameterization derived from $\ln \left(\mathrm{k}_{\mathrm{w}}\right)$ versus $\ln (\mathrm{U})$; this resulted in $\mathrm{k}_{660}=0.52( \pm 0.08) \mathrm{U}_{10}^{2}$.

[17] Many parameterizations of gas exchange with wind speed have been reported, and dependencies in wind speed

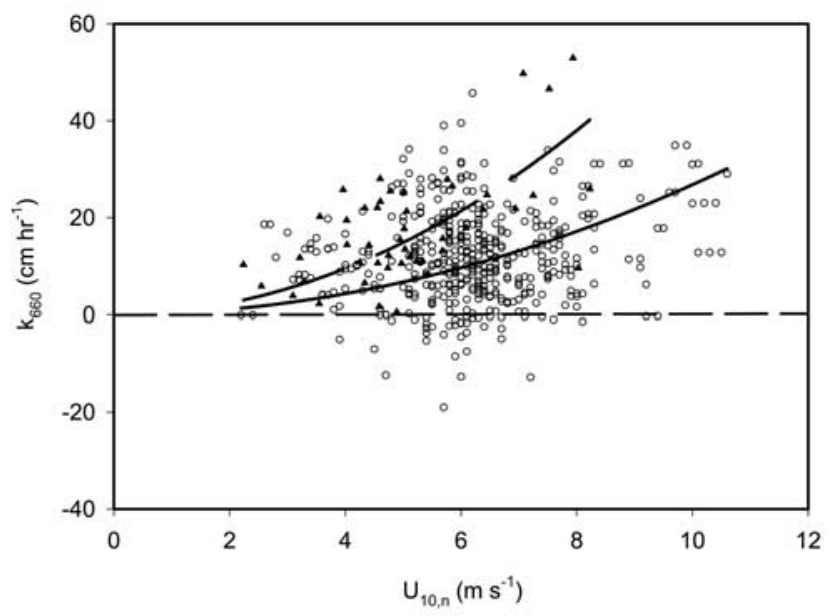

Figure 4. Gas transfer rates $\left(\mathrm{cm} \mathrm{hr}^{-1}\right)$ derived from gradient measurements of DMS flux (black triangles) and eddy correlation measurements of $\mathrm{CO}_{2}$ flux (open circles). The dashed line is the gas transfer parameterization based on DMS measurements $\left(\mathrm{k}_{660}=0.60 \mathrm{U}_{10}^{2}\right)$, and the solid line is the gas transfer parameterization based on $\mathrm{CO}_{2}$ measurements $\left(\mathrm{k}_{660}=0.28 \mathrm{U}_{10}^{2}\right)$, derived from McGillis et al. [2001]. 


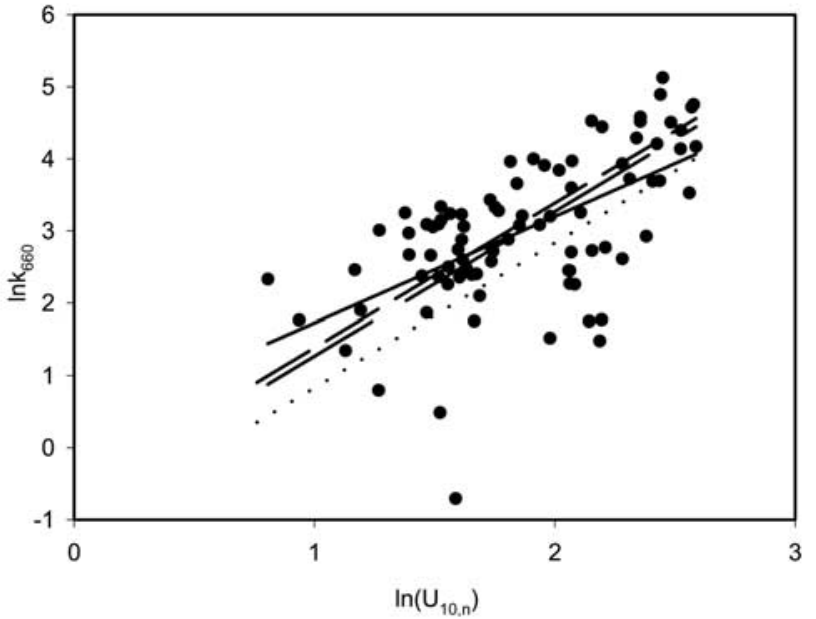

Figure 5. Ln transformed $\mathrm{k}_{660}$ versus $\ln$ transformed $\mathrm{U}_{10, \mathrm{n}}$. The solid line is the least squares fit through the data: $\mathrm{k}_{660}=1.28 \mathrm{U}_{10}^{1.47}$. The short dashed line is the equation based on eddy correlation measurements of $\mathrm{CO}_{2}$ flux: $\mathrm{k}_{660}=$ $0.54 \mathrm{U}_{10}^{2}$ from Jacobs et al. [1999]. The long dashed line is the quadratic fit through the merged data set: $\mathrm{k}_{660}=$ $0.48 \mathrm{U}_{10}^{2}$. The dotted line is the Wanninkhof [1992] fit: $\mathrm{k}_{660}=0.31 \mathrm{U}_{10}^{2}$.

vary from linear [Liss and Merlivat, 1986] to quadratic and cubic [Wanninkhof, 1992; Jacobs et al., 1999; Nightingale et al., 2000; Wanninkhof and McGillis, 1999; McGillis et al., 2001]. Monahan and Spillane [1984] proposed that gas transfer is proportional to whitecap coverage and that white cap coverage scales approximately with $\mathrm{U}^{3}$. Laboratory studies of Asher et al. [1996] have shown a linear, gasspecific, dependence of gas transfer with whitecaps, implying that gas exchange could show a cubic relation to wind speed. Indeed, Wanninkhof and McGillis [1999] and McGillis et al. [2001] showed that the exchange of $\mathrm{CO}_{2}$ over a wide range of wind speeds up to $16 \mathrm{~m} \mathrm{~s}^{-1}$ was described well by a cubic wind speed dependence of $\mathrm{k}$. However, a cubic fit through the merged GasEx01-GF/DMS and FAIRS-REA/DMS data, in the form of $\ln y=\operatorname{lna}+3 \ln x$, did not yield a better fit with the observed data $\left(\mathrm{R}^{2}<0.1\right)$ than a quadratic fit.

[18] Using the merged data set and following the most common approach of relating $\mathrm{k}_{\mathrm{W}}$ to the square of $\mathrm{U}_{10}$ it is possible to describe the exchange of DMS up to a wind speed of $13 \mathrm{~m} \mathrm{~s}^{-1}$ by

$$
\left.\mathrm{F}_{\mathrm{DMS}}=0.48(1-\gamma) \mathrm{U}_{10}^{2} 660 / \mathrm{Sc}_{\mathrm{DMS}}\right)^{-\mathrm{n}} \Delta \mathrm{C} \quad \mathrm{R}^{2}=0.31,
$$

where $\mathrm{Sc}_{\text {DMS }}$ can be derived from Saltzman et al. [1993]. This relationship between gas transfer and wind speed is in good agreement with the parameterization found by Jacobs et al. [1999]: $\mathrm{k}_{660}=0.54( \pm 0.08) \mathrm{U}_{10}^{2}$, determined from eddy correlation measurements of $\mathrm{CO}_{2}$ flux over a shelf sea.

[19] However, it should be emphasized that although the GasEx01-GF/DMS and FAIRS-REA/DMS data are in agreement in terms of the derived parameterizations and the homogeneous variance, there is no reason to assume that the FAIRS-GF/DMS or GasEx-EC/CO $\mathrm{CO}_{2}$ results are

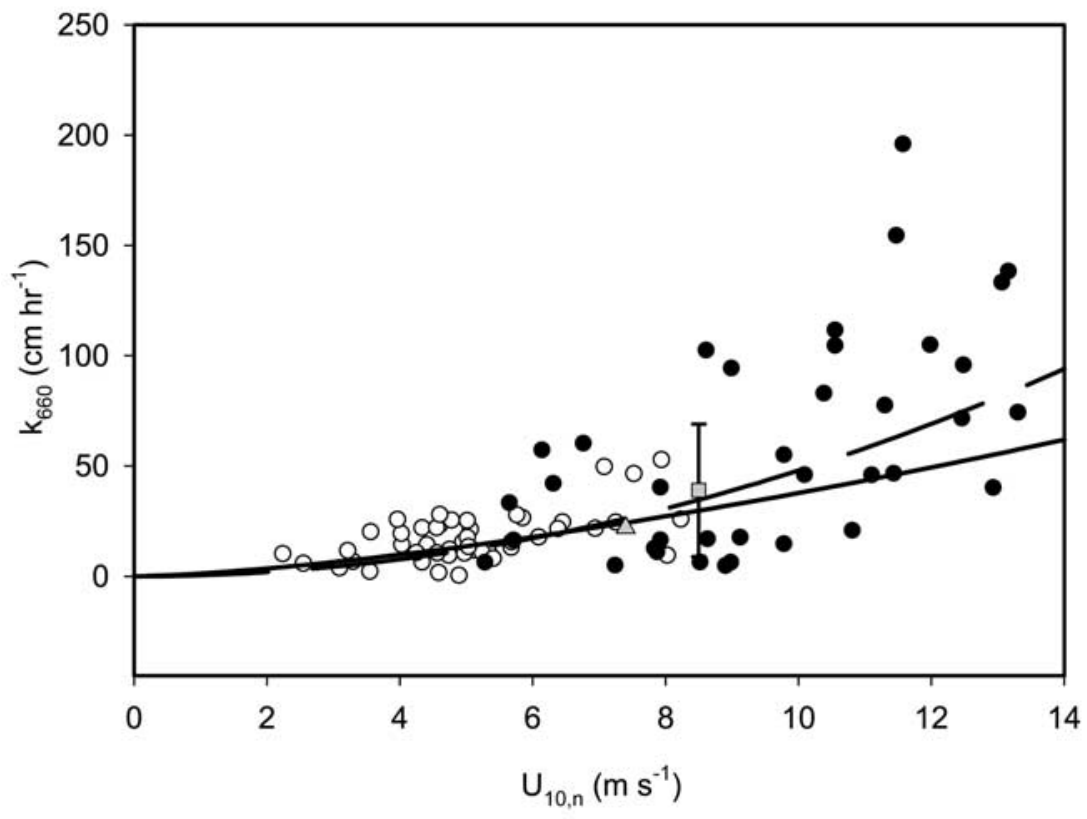

Figure 6. Merged GasEx-2001-GF (open circles) and FAIRS-REA results (solid circles). The shaded square is the average of gas transfer velocities derived from DMS gradient measurements during the GasEx-1998 cruise $(n=3)$. The shaded triangle is the global mean transfer rate determined from ${ }^{14} \mathrm{C}$ [Broecker et al., 1985]. Transfer velocities are normalized to the transfer velocity of $\mathrm{CO}_{2}$ in water at $20^{\circ} \mathrm{C}$ with a salinity of $35 \%$. The solid line is the least squares fit through the data: $\mathrm{k}_{660}=1.28 \mathrm{U}_{10}^{1.47}$. The dashed line is the quadratic fit through the merged data set: $\mathrm{k}_{660}=0.48 \mathrm{U}_{10}^{2}$. 
erroneous. Moreover, the variance in the FAIRS-GF/DMS and the GasEx-EC/CO $\mathrm{CO}_{2}$ data sets is not statistically different from the variance of the two other data sets $(\mathrm{P}>5 \%)$.

[20] It is questionable whether equation (5) is a valid description of gas exchange over the Pacific Ocean since it is based on measurements made in marine geographical provinces with different characteristics. Differences in environmental conditions during the FAIRS and GasEx2001 cruises might have affected the applied techniques. The FAIRS cruise was conducted on the edge of the Californian current where the occurrence of strong winds and high swell is common, while the equatorial Pacific is typically a low wind speed area where small waves prevail. The effect of swell and waves on the applicability of REA and GF techniques, more specifically on the models that these techniques are based upon, is not yet fully understood. In addition, the Californian current is much more biologically productive, and it is likely that there are more surfactants in this area than in the equatorial Pacific. Surfactants are known to suppress gas exchange significantly [Frew, 1997].

[21] Although the GasEx01-EC/CO $\mathrm{CO}_{2}$ and GasEx01GF/DMS data sets agree, GF/DMS measurements made beyond $6 \mathrm{~m} \mathrm{~s}^{-1}$ suggest a strong increase of transfer rates, which depends mostly on the three DMS measurements with $\mathrm{k}_{660}$ above $40 \mathrm{~cm} \mathrm{hr}^{-1}$. This increase is not observed in the $\mathrm{EC} / \mathrm{CO}_{2}$ measurements, resulting in a discrepancy between the GasEx01-EC/CO $\mathrm{CO}_{2}$ and GasEx01-GF/DMS parameterizations. The different sizes of the data sets and the larger wind speed range over which the $\mathrm{EC} / \mathrm{CO}_{2}$ measurements were made are likely reasons for the discrepancy between the two parameterizations. The small number of GF/DMS measurements at elevated wind speeds does not allow a conclusion other than that the data sets agree within uncertainty. However, processes such as biogeochemical conversions in the sea surface microlayer and bubble mediated transport may cause a difference in the exchange rates of two gas species; such effects are not taken into account in the parameterizations.

[22] The GasEx01 results clearly show that it is not possible to rely on the use of a single technique for the description of air-sea gas exchange. Moreover, even when it is possible to make reliable field measurements of gas fluxes, there will still be a significant degree of uncertainty when gas transfer velocities are parameterized as a function of wind speed alone. It is unlikely that this uncertainty will be reduced by more measurements alone, unless other factors controlling exchange within the source area are taken into account.

[23] It seems that most field measurements (GasEx98/01, ASGAMAGE, FAIRS) indicate higher gas transfer rates than those derived from the Liss and Merlivat [1986] parameterization (which can be approximated by the quadratic dependence: $\mathrm{k}_{660}=0.17 \mathrm{U}^{2}$ ); this would mean that the current IPCC estimate of the $\mathrm{CO}_{2}$ budget, which is based on the average of transfer velocities derived from Wanninkhof [1992] and Liss and Merlivat [1986], is at the low side. Moreover, studies of sulfur cycling often estimate the atmospheric burden of DMS on the basis of fluxes calculated by using the Liss and Merlivat [1986] parameterization of $\mathrm{k}_{\mathrm{w}}$ as a function of wind speed. The in situ measurements during GasEx-2001 imply that the atmospheric burden of DMS can be underestimated significantly by this approach. Gas transfer parameterizations that are derived from micrometeorological measurements of gas fluxes in the field tend to result in higher transfer rates than those based on the conventional Liss and Merlivat gas transfer parameterization. The emission of DMS from the ocean to the atmosphere could well be higher than until now was commonly thought. However, field measurements show a high degree of scatter that cannot readily be accounted for by wind speed and water temperature alone. It has to be concluded that in situ measurements do not yet permit an accurate parameterization of gas transfer as a function of wind speed.

\section{Conclusion}

[24] The gas transfer velocities derived from in situ measurement of DMS and $\mathrm{CO}_{2}$ fluxes during GasEx-2001 agree within uncertainty. However, averages in the form of a functional fit of $\mathrm{k}_{660}$ versus $\mathrm{U}_{10}$ through the data sets result in a large discrepancy between parameterizations. This emphasizes the danger of relying on a single technique, or data set, to obtain gas budgets. The measurement precision of both techniques during GasEx-2001 seems to agree well, which is encouraging because it might help one or both of the techniques to improve precision and or accuracy in the future.

[25] Acknowledgments. The authors wish to thank the crew of R/V Ronald H. Brown for their outstanding efforts. Funding for this work came from the Netherlands Organization for Scientific Research (NWO) and from the NOP project 951203: "Micrometeorology of air/sea fluxes of carbon dioxide. This work was supported by the Global Carbon Cycle project of the NOAA Office of Global Programs grant NA17RJ1223, National Science Foundation grant OCE-9986724, and NSF grant ATM-0120569. This is Woods Hole Oceanographic Institution contribution 10997.

\section{References}

Andreae, M. O. (1990), Ocean atmosphere interactions in the global biogeochemical sulfur cycle, Mar. Chem., 30, 1-29.

Andreae, M. O., and P. J. Crutzen (1997), Atmospheric aerosols: Biogeochemical sources and role in atmospheric chemistry, Science, 276, 10521058 .

Asher W. E., L. M. Karle, B. J. Higgins, P. J. Farley, E. C. Monahan, and I. S. Leifer (1996), The influence of bubble plumes on air-seawater gas transfer velocities, J. Geophys. Res., 101, 12,027-12,041.

Ayers, G. P., and R. W. Gillett (2000), DMS and its oxidation products in the remote marine atmosphere: Implications for climate and atmospheric chemistry, J. Sea Res., 43, 275-286.

Bates, T. S., K. C. Kelly, and J. E. Johnson (1993), Concentrations and fluxes of dissolved biogenic gases (DMS, $\mathrm{CH}_{4}, \mathrm{CO}, \mathrm{CO}_{2}$ ) in the equatorial $\mathrm{Pa}$ cific during the SAGA 3 experiment, J. Geophys. Res., 98, 16,969$16,977$.

Broecker, W. S., T. H. Peng, G. Ostlund, and M. Stuiver (1985), The distribution of bomb radiocarbon in the ocean, J. Geophys. Res., 90, $6953-6970$

Businger, J. A., J. C. Wyngaard, Y. Izumi, and E. F. Bradley (1971), Flux profile relationships in the atmospheric surface layer, J. Atmos. Sci., 28, $181-189$.

Dacey, J. W. H., S. G. Wakeham, and B. Howes (1984), Henry's law constants for dimethylsulfide in freshwater and seawater, Geophys. Res. Lett., 11, 991-994.

Dacey, J. W. H., F. A. Howes, A. F. Michaels, and S. G. Wakeham (1998), Temporal variability of dimethylsulfide and dimethylsulfoniopropionate in the Sargasso Sea, Deep Sea Res., Part I, 45, 2085-2104.

Edson, J. B., and C. W. Fairall (1998), Similarity relationships in the marine atmospheric surface layer for terms in the TKE and scalar variance budgets, J. Atmos. Sci., 55, 2311-2328.

Frew, N. M. (1997), The role of organic films in air-sea gas exchange, in The Sea Surface and Global Change, edited by P. S. Liss and R. A. Duce, pp. 121-171, Cambridge Univ. Press, New York. 
Hintsa, E. J., J. W. H. Dacey, W. R. McGillis, J. B. Edson, C. J. Zappa, and H. J. Zemmelink (2004), Sea-to-air fluxes from measurements of the atmospheric gradient of dimethylsulfide and comparison with simultaneous relaxed eddy accumulation measurements, J. Geophys. Res., 109, C01026, doi:10.1029/2002JC001617.

Jacobs, C. M. J., W. Kohsiek, and W. A. Oost (1999), Air-sea fluxes and transfer velocity of $\mathrm{CO}_{2}$ over the North Sea: Results from ASGAMAGE, Tellus, Ser. B, 51, 629-641.

Kettle, A. J., and M. O. Andreae (2000), Flux of dimethylsulfide from the oceans: A comparison of updated data sets and flux models, J. Geophys. Res., 105, 26,793-26,808.

Kettle, A. J., et al. (1999), A global database of sea surface dimethylsulfide (DMS) measurements and a procedure to predict sea surface DMS as a function of latitude, longitude, and month, Global Biogeochem. Cycles, $13,399-444$

Kondo, J. (1975), Air-sea bulk transfer coefficients in diabatic conditions, Boundary Layer Meteorol., 9, 91-112.

Liss, P. S. (1999), Take the shuttle from marine algae to atmospheric chemistry, Science, 285, 1217-1218

Liss, P. S., and L. Merlivat (1986), Air-sea gas exchange rates: Introduction and synthesis, in The Role of Air-Sea Exchange in Geochemical Cycling edited by P. Buat-Ménard, pp. 113-129, D. Reidel, Norwell, Mass.

Liss, P. S., A. J. Watson, M. I. Liddicoat, G. Malin, P. D. Nightingale, S. M Turner, and R. C. Upstill-Goddard (1993), Trace gases and air-sea exchanges, Philos. Trans. R. Soc. London, 343, 531-541.

Liu, W. T., K. B. Katsaros, and J. A. Businger (1979), Bulk parameterizations of the air-sea exchange of heat and water vapor including the molecular constraints at the interface, J. Atmos. Sci., 36, 17221735 .

McGillis, W. R., J. W. H. Dacey, N. M. Frew, E. J. Bock, and R. K. Nelson (2000), Water-air flux of dimethylsulfide, J. Geophys. Res., 105, 11871193.

McGillis, W. R., J. B. Edson, J. D. Ware, J. W. H. Dacey, J. E. Hare, C. W. Fairall, and R. Wanninkhof (2001), Carbon dioxide flux techniques performed during GasEx-98, Mar. Chem., 75, 267-280.

Monahan, E. C., and M. C. Spillane (1984), The role of oceanic whitecaps in air-sea gas exchange, in Gas Transfer at Water Surfaces, edited by W. Brutsaert and G. H. Jirka, pp. 495-503, D. Reidel, Norwell, Mass.

Monin, A. S., and A. M. O. Obukhov (1954), Fundamentale Gesetzmäßigkeiten der turbulenten vermischung in der bodennahen schicht der atmosphäre, in Sammelband zur Statistischen Theory der Turbulenz, edited by H. Goering, pp. 199-226, Dtsch. Akad. der Wissensch. zu Berlin, Berlin.

Nightingale, P. D., G. Malin, C. S. Law, A. J. Watson, P. S. Liss, M. I. Liddicoat, J. Boutin, and R. C. Upstill-Goddard (2000), In situ evaluation of air-sea gas exchange parameterizations using novel conservative and volatile tracers, Global Biogeochem. Cycles, 14, 373-387.
Paulson, C. A. (1970), The mathematical representation of wind speed and temperature profiles in the unstable atmospheric surface layer, J. Appl. Meteorol., 9, 857-861

Putaud, J. P., and B. C. Nguyen (1996), Assessment of dimethylsulfide seaair exchange rate, J. Geophys. Res., 101, 4403-4411.

Quinn, P. K., D. S. Covert, T. S. Bates, V. N. Kapustin, D. C. Ramsey-Bell, and L. M. McInnes (1993), Dimethylsulfide/cloud condensation nuclei/ climate system: Relevant size-resolved measurements of the chemical and physical properties of atmospheric aerosol particles, J. Geophys. Res., 98, $10,411-10,427$.

Saltzman, E. S., D. B. King, K. Holmen, and C. Leck (1993), Experimental determination of the diffusion coefficient of dimethylsulfide in water, J. Geophys. Res., 98, 16,481-16,486.

Wanninkhof, R. (1992), Relationship between wind speed and gas exchange over the ocean, J. Geophys. Res., 97, 7373-7382.

Wanninkhof, R., and W. R. McGillis (1999), A cubic relationship between air-sea CO2 exchange and wind speed, Geophys. Res. Lett., 26, 18891892.

Yvon, S. A., E. S. Saltzman, T. S. Bates, and D. J. Cooper (1996), Atmospheric sulfur cycling in the tropical Pacific marine boundary layer $\left(12^{\circ} \mathrm{S}\right.$, $\left.135^{\circ} \mathrm{W}\right)$ : A comparison of field data and model results: 1. Dimethylsulfide, J. Geophys. Res., 101, 6899-6910.

Zemmelink, H. J., W. W. C. Gieskes, W. Klaassen, H. W. de Groot, H. W. J. de Baar, J. W. H. Dacey, E. J. Hintsa, and W. R. McGillis (2002), Simultaneous use of relaxed eddy accumulation and gradient flux techniques for the measurement of sea-to-air exchange of dimethylsulfide, Atmos. Environ., 36, 5709-5717.

Zemmelink, H. J., W. Klaassen, W. W. C. Gieskes, H. J. W. de Baar, H. W. de Groot, E. J. Hintsa, J. W. H. Dacey, and W. R. McGillis (2004), Relaxed eddy accumulation measurements of the sea-to-air transfer of dimethylsulfide over the northeastern Pacific, J. Geophys Res., 109(C1), C01025, doi:10.1029/2002JC001616

J. W. H. Dacey and H. J. Zemmelink, Department of Biology, Woods Hole Oceanographic Institution, MS 32, Woods Hole, MA 02543, USA. (jdacey@whoi.edu; hzemmelink@whoi.edu)

H. J. W. de Baar, H. W. de Groot, W. W. C. Gieskes, and W. Klaassen, Marine Biology, University of Groningen, Kerklaan 30, P.O. Box 14 NL-9750 AA Haren, Netherlands. (debar@nioz.nl; h.w.de.groot@boil. rug.nl; w.w.c.gieskes@boil.rug.nl; w.klaassen@boil.rug.nl)

E. J. Hintsa, Marine Chemistry and Geochemistry Department, Woods Hole Oceanographic Institution, MS 25, Woods Hole, MA 02543, USA. (ehintsa@whoi.edu)

W. R. McGillis, Applied Ocean Physics and Engineering Department, Woods Hole Oceanographic Institution, MS 12, Woods Hole, MA 02543, USA. (wmcgillis@whoi.edu) 